\title{
Smart Irrigation and Crop Planning System: using Arduino Microcontroller
}

\author{
Ekata Ghadage $^{1}$, Vibhavari Kharate ${ }^{2}$, Parnika Mane ${ }^{3}$, Samruddhi Pimpale ${ }^{4}$ \\ Student, Computer Engineering, Pimpri Chinchwad College of Engineering, Pune, India 1,2,3,4
}

\begin{abstract}
Developing water shortage, because of growing populations and varying natural conditions, places stress on irrigation structures, which frequently are the primary consumptive water users. Therefore, water resources control to enhance the allocation of restrained water materials is critical. With the effect of weather alternate in India, majority of the agricultural vegetation are being badly affected in terms in their performance over duration of final two decades. Predicting the crop yield nicely beforehand of its harvest might help the coverage makers and farmers for taking appropriate measures for advertising and marketing and garage. Such predictions will also help the associated industries for planning the logistics of their business. Several strategies of predicting and modeling crop yields have been evolved in the beyond with varying fee of achievement, as those don't take into account traits of the climate, and are mainly empirical. In this proposed system we are Using Discrete Cuckoo Search Algorithm in which we are planning and water allocation to crop in any whether condition, we checking weather environment and depend on that we are give a water supply to our crops.
\end{abstract}

Keywords: Climate, agricultural productivity, Crop Production, prediction.

\section{INTRODUCTION}

Agricultural systems pose many challenges and issues that may be formulated as optimization troubles. Such problems encompass crop choice, united states of America-huge crop making plans, irrigation making plans, vegetable production, beef manufacturing, wildlife and cattle management, and sugarcane transportation. For this article we recognition on crop making plans and water management [1]. Crop manufacturing is a complex phenomenon thatis encouraged by way of agro-climatic enters parameters. Agriculture input parameters varies from field to field and farmer to farmer. Collecting such records on a larger location is a frightening mission. However, the climatic information accumulated in India at each 1sq.m place in special components of the district is tabulated via Indian Meteorological branch. The large such records sets can be used for predicting their influence on predominant crops of that unique district or location. There is one of a kind forecasting methodologies evolved and evaluated via the researchers everywhere in the international in the field of agriculture or associated sciences.

Water scarcity is a global hassle, but its miles maximum extreme in arid and semi-arid regions. Often, increasing water demands because of populace boom similarly worsen the problem [1]. At the worldwide degree, the rural quarter is the largest purchaser of water resources. Therefore, this zone is closely impacted by means of water shortage and yield reduction may additionally bring about a decline of meals security worldwide [2]. Therefore, improvements in agricultural water control are wished. Optimization of irrigation structures and improvement of water useful resource allocations through appropriate multi-cropping styles and irrigation scheduling are considered as important responses to deal with water shortage [3]. Iran is a water scarce country due to the low precipitation, excessive evaporation and the temporal and spatial version of rainfall. Consistent with the global Water control Institute (IWMI), Iran is furthermore one of the nations beneath important water shortage situations [4].

Given a farmland, a water resource, and a listing of plants, the goal is to decide the gold standard (or close to topquality) cropping styles and irrigation plans. This is to determine the nice set of vegetation to be cultivated over the season (commonly 12 months), the place allocation for every of these crops, the sequencing of vegetation (if several vegetation are to be sequentially cultivated over the same piece of land within the equal season), and the irrigation plans. All decided for you to reap some set of goals. Generally, those desires contain the maximization of internet earnings, the minimization of funding, the maximization of total vicinity cultivated, and/or the minimization of irrigation water. The primary entities of the venture contain the farmland itself, the labor, the water resource(s), and a list of crops. The foremost properties and characteristics of each such entity together with the interactions amongst them want to be determined a-priori. As an instance, for the farmland it may be had to decide its location, its topographical homes, soil characteristics inclusive of fertility, and the type and amount of human hard work available. As for the water aid we might also want to determine such homes as the most permissible month-to-month and annual release, whether or not it's far used for other purposes - together with irrigation, which include electricity era and the associated monetary utility. Some complete set of crops that can be feasibly cultivated 
Vol. 6, Issue 1, January 2017

in the area underneath research want to be decided. For each such crop some set of parameters that relate the crop to the given farmland and water useful resource are to be determined. These parameters involve the yield per unit location, water requirement, labor requirement, internet return for production of the crop, etc.

\section{LITERATURE REVIEW}

Several researchers have evolved optimization and simulation fashions for making plans and control of irrigation systems. Ghahraman and Sepaskhah [7] for example developed a stochastic dynamic programming optimization version for the most reliable allocation of water to a predetermined more than one cropping sample in Khorasan province, Iran. Raju and Kumar [8] carried out a genetic set of rules (GA) for irrigation planning of the Sri Ram Sagar assignment, in Andhra Pradesh, India. Kumar et al. [9] also proposed an irrigation allocation model to decide relative yield below a designated cropping pattern in Karnataka state, India the usage of a GA. similarly, Georgiou and Papamichail [10] advanced a nonlinear programming optimization version to decide the highest quality reservoir launch rules and the optimum cropping sample in Chalkidiki vicinity, Greece. Regulwar and Anand Raj [11] in the end a monthly multi goal genetic algorithm fuzzy optimization model for 2 conflicting targets of a multi reservoir machine within the Godavari river sub basin, in Maharashtra kingdom, India.

Agricultural researchers in Pakistan have shown that attempts of crop yield maximization thru pro-pesticide country regulations have caused a dangerously high pesticide usage. These research have mentioned poor correlation between pesticide usage and crop yield[1]. In their have a look at they have proven that how records mining incorporated agricultural statistics along with pest scouting, pesticide utilization and meteorological statistics are beneficial for optimization of pesticide usage. Thematic information associated with agriculture which has spatial attributes became suggested in one of the look at[6]. Their take a look at aimed toward discerning developments in agriculture production with references to the availability of inputs. ok- manner method turned into used to carry out forecasts of the pollution inside the ecosystem [4], the okay nearest neighbor became applied for simulating day by day precipitations and different weather variables [11], and distinctive feasible adjustments of the climate eventualities are analyzed using SVMs[13]. Information mining strategies are frequently used to take a look at soil characteristics. As an example, the okay-approach technique is used for classifying soils in aggregate with GPS-primarily based technology [14]. Apples have been checked the use of special approaches earlier than sending them to the market.[9], makes use of a k-method method to examine colour pix of end result as they run on conveyor belts. [12] uses X-ray snap shots of apples to monitor the presence of water cores, and a neural community is trained for discriminating among right and awful apples. Spatial data mining delivered especially decision tree set of rules applying to agriculture land grading [15]. He mixed spatial records mining techniques with expert system techniques and implemented them to set up clever agriculture land grading statistics gadget.

Tang and Mays (1998) carried out genetic algorithms to most effective operation of soil aquifer treatment (SAT) systems for finding premier water software time and drying time to maximize infiltration for a predetermined starting influent rate of waste water. They concluded that GA-SAT version plays higher as compared to the successive approximation linear quadratic regulator set of rules. Chang and Chen (1998) applied two sorts of genetic algorithms, particularly, actual-coded and binarycoded and applied to the optimization of a flood manage reservoir model. It's miles found that both the genetic algorithms are more efficient and sturdy than the random seek method. They but observed that the real-coded GA changed into appearing higher in phrases of efficiency and precision compared to the binary-coded GA. Wardlaw and Sharif (1999) evaluated numerous formulations of a genetic set of rules for four-reservoir, deterministic, finite-horizon trouble. They also considered a nonlinear 4-reservoir hassle, one with prolonged time horizons and a complicated ten-reservoir trouble. They concluded that genetic set of rules technique is greater robust. Hilton and Culver (2000) as compared methods - additive penalty method (APM) and multiplicative penalty technique (MPM) - for constraint managing in the genetic algorithm framework. They concluded that MPM is a more robust approach. Sharif and Wardlaw (2000) supplied genetic algorithm technique for optimization of multireservoir structures for a case take a look at in Indonesia and its effects were in comparison with those of discrete differential dynamic programming. They concluded that genetic algorithm results are toward the ideal. $\mathrm{Wu}$ and Simpson (2001) carried out messy genetic algorithm for most advantageous design and rehabilitation of a water distribution device through analyzing benchmark issues. They determined that wide variety of layout trials required for the messy genetic set of rules are fewer than for the other genetic algorithms. Gentry et al. (2001) applied genetic set of rules in combination with a numerical modeling approach to determine each the spatial distribution and the flux represented by means of the accretion factor of the groundwater flow equation. Yoon and Shoemaker (2001) carried out a real-coded genetic set of rules (RGA) coupled with newly developed operators: directive recombination and screened substitute for an insitu bioremediation of ground water. They concluded that RGA plays better than the binary-coded GA. Nicklow et al. (2003) advanced an greatest control technique for minimizing sediment aggradation and degradation. The simulation version, HEC-6isused tosolve the governing hydraulic andsediment constraints, even as the genetic set of rules is used to clear up the overall manage problem. The methodology is validated with a hypothetical and a actual case study proving the sensible application of the technique as a selection-making tool for sedimentation manage. 


\section{PROPOSED SYSTEM}

Optimization concerns many disciplines with a extensive range of packages. As time, cash and sources are always restricted, optimization is ever-increasingly important. For instance, energy-saving designs and green answers to many commercial troubles require a paradigm shift in wondering and design exercise. However, people need clever and intelligent merchandise, and computational intelligence has emerged as a promising region with doubtlessly wide ranging impact. in recent times machine studying frequently makes use of optimization algorithms to enhance its mastering overall performance, at the same time as optimization also borrows ideas from device gaining knowledge of which include statistical studying idea and neural networks. in this article, we can recognition at the creation of cuckoo search as a powerful, nature-stimulated meta heuristic algorithm for optimization and computational intelligence.

In this proposed system we are going check all weather condition and depending on that we allocating water supply for crops. As per the requirements we provide water supply to them and another thing in that is because of the changing environment crops are going to be effect very badly. So this thing is also done in our proposed system, this is very effective way for the crops management and by using this we give proper output.

Because climatic facts for the overall operation life of the reservoir are not to be had a artificial time collection is constructed for rainfall, evapotranspiration and inflow. Furthermore, rainfall, evapotranspiration and inflow are taken into consideration to be stochastic. The optimization model is therefore run for predicted values of the aforementioned parameters corresponding to one-of-akind possibilities.

The model is advanced to decide the most excellent cropping sample and irrigation scheduling for the fundamental vegetation within the look at region. The reservoir garage constitutes the device's kingdom variable, whereas the machine's inputs, normally called choice variables, are the cultivated regions, and the water releases from the reservoir to fulfill irrigation requirements for each crop during every time $\mathrm{c}$ programming language.

\section{SYSTEM ARCHITECTURE}

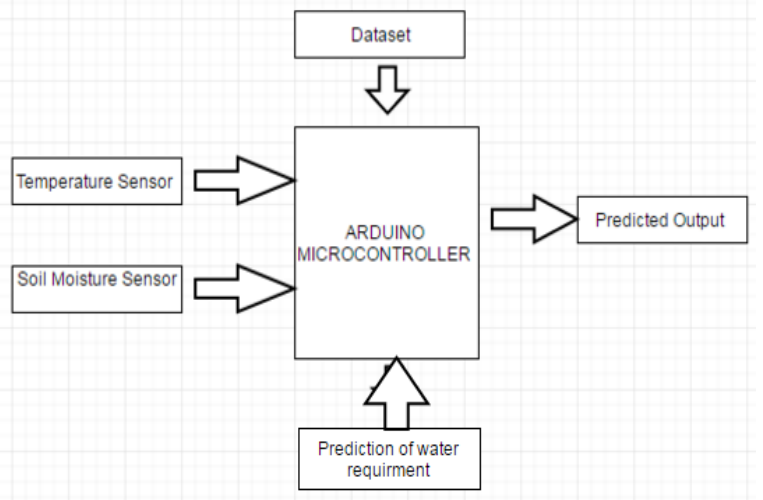

In this System We have used Dataset to calculate the Prediction of Crop Planning using the hardware sensor like Temperature Sensor and Soil moisture Sensor .Senses data is further send over Arduino to Computer /Machine .We will apply the Dataset and can predict the planning of crops will planted in the farm or land.

\section{DATASET}

Table 3 APPROXIMATE VALUES OF SEASONAL CROP WATER NEEDS

\begin{tabular}{|l|c|}
\hline \multicolumn{1}{|c|}{ Crop } & Crop water need (mmitotal growing period) \\
\hline Beans & $300-500$ \\
\hline Citrus & $900-1200$ \\
\hline Cotion & $700-1300$ \\
\hline Groundinut & $500-700$ \\
\hline Maize & $500-800$ \\
\hline Sorghum/milet & $450-650$ \\
\hline Soybean & $450-700$ \\
\hline Sunflowet & $600-1000$ \\
\hline
\end{tabular}

Table 1 - EFFECT OF MAJOR CLIMATIC FACTORS ON CROP WATER NEEDS

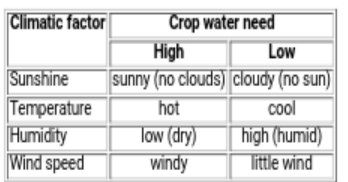

Table 2 - AVERAGE DAILY WATER NEED OF STANDARD GRASS DURING IRRIGATION SEASON (mm)

\begin{tabular}{|l|c|c|c|}
\hline Climatic zone & \multicolumn{3}{|c|}{ Mean daily temperature } \\
\cline { 2 - 4 } & low $\left(<15^{\circ} \mathrm{C}\right)$ & medilum $\left(15-25^{\circ} \mathrm{C}\right)$ & high $\left(>25^{\circ} \mathrm{C}\right)$ \\
\hline Desert//arid & 46 & $7-8$ & $9-10$ \\
\hline Semi-arid & 45 & $6-7$ & $8-9$ \\
\hline
\end{tabular}

\section{CONCLUSION}

Irrigation making plans trouble is solved the use of discrete Cuckoo search algorithm. In this example price of fitness characteristic is same to goal feature. Penalty feature method is used to convert the limited problem into an unconstrained trouble with an affordable penalty characteristic. When you consider that discrete cuckoo seek algorithm is dependent on diverse parameters along with populace, generations, move over and mutation possibilities diverse combinations are attempted.The present examine verified the ability use of records mining techniques in predicting the crop yield based on the climatic enter parameters.

\section{REFERENCES}

[1] Abdullah, A., Brobst, S, Pervaiz.I.,UmerM.,and A.Nisar.2004. Learning dynamics of pesticide abuse through data mining. Proceedings of Australian Workshop on Data mining and Web Intelligence, New Zealand, January.

[2] Dhanya,C.T. and D. Nagesh Kumar, 2009. Data mining for evolution of association rules for droughts and floods in India using climate inputs. J. of Geo. Phy.Res.114:1-15.

[3] Fernandes F.L., Jansle V.R., Rubens Augusto and Camargo L.(2011). Sugarcane yield estimates using time series analysis of spot vegetation images. Sci. Agric. (Piracicaba, Braz.)vol.68no. 2

[4] Jorquera H, Perez R, Cipriano A, Acuna G(2001). Short term forecasting of air pollution episodes. In. Zannetti $\mathrm{P}$ (eds) Environmental Modeling 4. WITPress, UK. 
[5] Jun Wu, AnastasiyaOlesnikova, Chi- Hwa Song, Won Don Lee (2009).The Development and Application of Decision Tree for Agriculture Data. IITSI :16-20.

[6] KiranMai,C., Murali Krishna, I.V., and A.VenugopalReddy,2006.Data Mining of Geospatial Database for Agriculture Related Application. Proceedings of Map India. New Delhi.(http://www.gisdevelopment.net/proceedings/mapindia/2006/ agriculture/mi06agri_12 4.htm).

[7] Kannan, M. Prabhakaran S and P. Ramachandran (2011).Rainfall forecasting using data mining technique. International Journal of Engineering and Technology Vol.2 (6), 2010, 397-401.

[8] Khan Mohammad A.,Md. Zahid-ul Islam and MohsinHafeez (2011). Evaluating the Performance of Several Data Mining Methods for Predicting Irrigation Water requirement. Proceedings of the Tenth Australasian Data Mining conference (AusDM2012), Sydney, Australia.199-207.

[9] Leemans,V.,Destain,M.F.,2004.A real-time grading method of apples based on features extracted from defects. J. Food Eng.61, 83- 89.

[10] Quinlan,J.R.(1985b). Decision trees and multi-valued attributes. In J.E. Hayes \&

[11] D.Michie (Eds.), Machine intelligence 11. Oxford University Press (in press).

[12] Rajagopalan B. Lall U (1999) A k- nearestneighbor daily precipitation and other weather variables. WatRes Research 35 (10) $: 3089-3101$.

[13] Shahin, M.A., Tollner, E.W., McClendon, R.W. Arabnia, H.R., (2002). Apple classification based on surface bruises using image processing and neural networks. Trans. ASAE 45, 1619-1627. 